\title{
SITUASI BAHASA SEBAGAI ALAT UNTUK PERENCANAAN BAHASA NASIONAL
}

\author{
Muhammad Ridlo ${ }^{1}$, Rosaria Mita Amalia ${ }^{2}$, Mudiyati Rahmatunnisa ${ }^{3}$ \\ Program Pasca Sarjana Kebijakan Publik \\ Fakultas Ilmu Sosial dan Ilmu Politik \\ Universitas Padjadjaran \\ mridlo29@gmail.com¹, rosariamitaamalia@unpad.ac.id², mudiyati@yahoo.com³
}

\begin{abstract}
ABSTRAK
Analisis situasi bahasa merupakan proses untuk menentukan perencanaan bahasa di sebuah negara. Selain dengan menggunakan hasil analisis situasi bahasa di dalam negeri, hasil analisis situasi bahasa di luar negeri pun dapat dimanfaatkan sebagai informasi tambahan dan juga referensi dalam perencanaan bahasa. Makalah ini akan menggambarkan bagaimana situasi bahasa di berbagai negara dengan tujuan untuk memberikan informasi mengenai situasi bahasa yang berlaku di negara maju dan berkembang. Pendeskripsian situasi bahasa di berbagai negara pun dapat dimanfaatkan sebagai acuan dalam perencanaan bahasa sehingga hasil yang dapat diperoleh dari makalah ini yakni diharapkan dapat bermanfaat dalam perencanaan bahasa di Indonesia sehingga kebijakan mengenai bahasa Indonesia dapat ditingkatkann dan sesuai dengan situasi bahasa yang terjadi saat ini.
\end{abstract}

Kata kunci: Situasi bahasa, kebijakan bahasa, bahasa Indonesia

\section{ABSTRACT}

Language situation analysis is a process for determining language planning in a country. In addition to using the results of analysis of the language situation in the country, the results of the analysis of the language situation abroad can also be used as additional information and also references in language planning. This paper will describe how the language situation in various countries with the aim of providing information about the situation of the language prevailing in developed and developing countries. The description of language situations in various countries can be used as a reference in language planning so that the results that can be obtained from this paper are expected to be useful in language planning in Indonesia so that policies regarding Indonesian can be improved and in accordance with the current language situation.

Keywords: Language situation, language policy, Indonesian language

\section{Pendahuluan}

Menurut Corson dalam Kucukoglu (2013), kebijakan bahasa nasional merupakan seperangkat prinsip yang disepakati secara nasional yang memungkinkan pengambil keputusan untuk membuat pilihan tentang masalah bahasa dengan cara yang rasional, komprehensif dan seimbang. Kebijakan bahasa pun merupakan seperangkat prinsip yang disepakati para pemangku kepentingan, memungkinkan pengambilan keputusan tentang isu-isu bahasa dan literasi dari sistem pendidikan formal di semua tingkatan: anak usia dini, primer, sekunder, dan pendidikan guru. Tempat dan sifat perencanaan bahasa di bidang pendidikan adalah salah satu dimensi kunci hubungan antara bahasa dan kehidupan sosial yang membuat pemerintah dapat menentukan pilihan (Liddicoat dalam Kucukoglu, 2013).
Menurut Azis, kebijakan bahasa bertujuan untuk menjaga keberlangsungan komunikasi warga negara tanpa menimbulkan gejolak sosial dan emosional yang mengganggu stabilitas negara. Sehingga, fungsi dari adanya kebijakan bahasa adalah untuk menciptakan bahasa persatuan yang dapat menciptakan perdamaian di sebuah negara.

Penentuan kebijakan bahasa ini kemudian dapat dikembangkan dengan penambahan kata 'nasional' agar memperjelas tujuan dari kebijakan tersebut (Sutama, 2018). Lanjutnya, apabila negara telah menjamin keberadaan suatu bahasa secara utuh, maka berakibat pada adanya hubungan pemerintah dengan masyarakat yaitu untuk melahirkan sejumlah kebijakan untuk menjamin terjadinya hak dan kewajiban masingmasing dalam mengelola bahasa yang ada. 
Pengelolaan bahasa yang ada salah satunya adalah dengan adanya penggunaan bahasa daerah. Penggunaan bahasa daerah seperti dalam hal pendidikan merupakan salah satu cara untuk melindungi bahasa daerah di samping juga fungsi bahasa daerah dapat digunakan untuk memperkaya bahasa nasional.

Terjaminnya hak dan kewajiban dalam pengelolaan bahasa daerah juga dapat bermanfaat dalam peningkatan keterampilan literasi karena setiap masyarakat mendapat kesempatan untuk memilih bahasa yang digunakan dan juga bermanfaat untuk mempromosikan ekspresi budaya, identitas dan mempertahankan warisan budaya.

Melalui penjelasan tersebut, maka makalah ini akan membahas bagaimana situasi bahasa yang berada di luar negeri dan bagaimana tindakan yang dilakukan atas situasi tersebut sehingga hasil yang diperoleh berdasarkan situasi bahasa yang berada di luar Indonesia akan bermanfaat bagi perencanaan bahasa di Indonesia.

\section{Metodologi Penelitian}

Penelitian ini menggunakan pendekatan deskriptif dengan tujuan menggambarkan situasi bahasa yang ada di berbagai negara. Pendekatan deskriptif ini akan menjelaskan persoalan bahasa di berbagai negara, tindakan yang dilakukan, dan reaksi masyarakat karena situasi bahasa yang berlaku atau karena kebijakan yang berlaku.

\section{Hasil dan Pembahasan}

\section{Situasi bahasa: Spanyol}

Di negara Spanyol, berdasarkan konstitusi 1978, setiap warga negara Spanyol sekitar 40 juta memiliki kewajiban untuk menggunakan bahasa Spanyol di seluruh wilayah nasional. Meskipun terdapat kewajiban tersebut, sekitar 40 persen warga spanyol pun menggunakan setidaknya satu bahasa lain, di antaranya bahasa Catalan, Basque, dan Galician.

Penggunaan bahasa ini telah diatur dalam undang-undang dan perencanaan bahasa yang dibuat tahun 1980 yang salah satu fungsinya adalah untuk mempromosikan bahasa yang menjadi varietas individu. Namun, meskipun telah diatur mengenai bahasa-bahasa di Spanyol, pada tahun 2001 UNESCO menjadikan bahasa Galician (yang terdapat di Spanyol) termasuk kategori bahasa yang terancam punah karena penyebaran antargenerasi mengalami kegagalan.

Permasalahan lain yang terdapat di negara Spanyol adalah istilah bahasa yang diperkirakan bertambah setiap tahunnya sebanyak 30.000 tidak berumur panjang. Salah satu faktornya adalah kurang varian penggunaan bahasa di bidang teknologi informasi, yang sebenarnya dapat dimanfaatkan untuk penyebaran kepada masyarakat.

\section{Situasi bahasa: Singapura}

Bahasa Inggris telah sejak 1987 menjadi media pengajaran di semua sekolah di Singapura, di antara populasi penduduk Singapura yang terdiri dari 76,8\% Tionghoa, 13,9\% Melayu, 7,9\% India, dan 1,4\% lainnya. Empat bahasa memiliki status resmi: Mandarin Cina, Melayu, Tamil - untuk mewakili tiga ras resmi utama, dengan bahasa Melayu menjadi bahasa nasional karena alasan historis - dan bahasa Inggris. Dari adanya empat bahasa yang berstatus resmi tersebut, penggunaan bahasa Inggris ini tidak termasuk di madrasah yang biasanya menggunakan bahasa kedua atau bahasa ibu.

Keaksaraan dalam bahasa Inggris telah meningkat dengan stabil selama beberapa dekade hingga 71\%. Bersamaan dengan ini adalah peningkatan penggunaan bahasa Inggris sebagai bahasa utama yang dominan di semua kelompok etnis. Bahasa Inggris juga jelas lebih dominan pada generasi muda. Pencampuran kode antara berbagai bahasa adalah ragam yang menonjol dari komunikasi intra dan interetnis.

Dalam bahasa Singapura yang berbeda-beda, bahasa Inggris mengalami perubahan dengan menampilkan ragam-ragam yang dihasilkan dari kontak bahasa, terutama melayu dan Hokkien. secara mengejutkan telah berevolusi untuk menampilkan fiturfitur yang dihasilkan dari kontak bahasa, terutama dari bahasa Melayu dan Hokkien (Bahasa Cina).

Sementara Bahasa Inggris Singapura yang lebih standar masih merupakan ragam yang ditemukan dalam situasi resmi, Bahasa Inggris Singapura yang biasa digunakan dalam sehari-hari, umumnya dikenal sebagai Singlish, secara luas digunakan lintas generasi dan kelas sosial, serta di media. Sebagai reaksi terhadap meningkatnya prevalensi Singlish, Gerakan berbahasa Inggris resmi diluncurkan pada tahun 2000.

\section{Situasi bahasa: Aljazair}

Setelah mencapai kemerdekaan dari Perancis pada tahun 1962, Aljazair meluncurkan serangkaian langkah-langkah untuk meng-Arab ulang negara tersebut. Kebijakan ini, yang disebut sebagai 'Arabisasi', secara umum merupakan reaksi terhadap dominasi budaya dan linguistik Perancis.

Tujuan dari kebijakan ini adalah untuk membalikkan dominasi bahasa Prancis dan memaksa penggunaan bahasa Arab pada semua sektor yang menggunakan bahasa Prancis seperti pendidikan, hokum, media, dan pemerintah. Peralihan bahasa tersebut pada akhirnya adalah untuk menggantikan bahasa Prancis menjadi bahasa Arab sebagai bahasa nasional. Tujuan lain dari mengarabkan Aljazair adalah untuk menghilangkan semua bahasa informal yaitu 


\section{Situasi Bahasa Sebagai Alat Untuk Perencanaan Bahasa Nasional (Muhammad Ridlo, Rosaria Mita Amalia, Mudiyati Rahmatunnisa)}

varietas lisan bahasa Arab dan Tamazight (Afrika), untuk memastikan persatuan nasional di sekitar pemerintah pusat. Terakhir, konstitusi Aljazair (1963, 1976, 1989, dan 1996) menolak multikulturalisme dan multilingualisme, yang menyatakan bahwa bahasa Arab adalah satu-satunya bahasa resmi dan nasional.

Keberadaan kebijakan tersebut nyatanya tidak membuat penduduk Aljazair menggunakan bahasa Arab karena kebijakan tersebut merepresentasikan upaya untuk merekonsiliasi keaslian, identitas nasional, dan modernisasi dan menghilangkan warisan masa lalu kolonial negara itu. Hingga saat ini, kebijakan bahasa yang diterapkan oleh Aljazair telah mengabaikan bahasa lain yang digunakan oleh orang Aljazair dengan alasan bahwa mereka merupakan ancaman bagi persatuan nasional (Tamazight) atau warisan masa lalu kolonial yang perlu dihilangkan (Perancis). Karena permasalahan tersebut, sampai dengan saat ini, Aljazair masih merupakan negara multibahasa dengan tiga bahasa yang bersaing yaitu bahasa Arab, Tamazight, dan

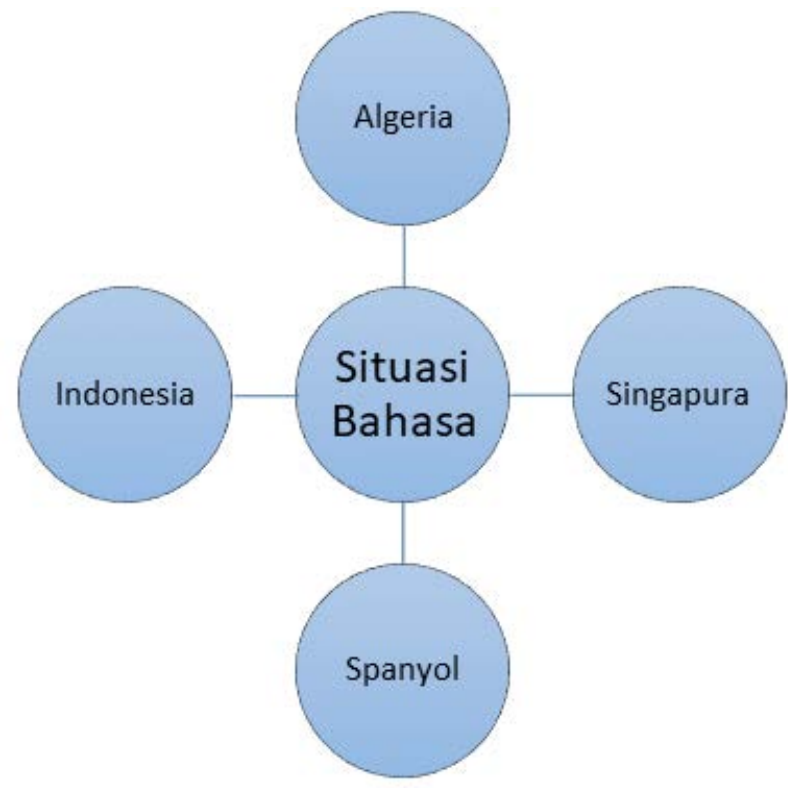

Prancis.

Gambar 1. Situasi bahasa di negara maju dan berkembang

\section{Bahasa Indonesia}

Keberadaan bahasa Indonesia mengalami pelemahan karena menguatnya penggunaan bahasa Inggris yang disebabkan arus globalisasi yang tinggi. Salah satu contoh penggunaan bahasa Inggris yang mengalami penguatan adalah penamaan nama tempat yang banyak menggunakan bahasa Inggris, yang dalam juknis Badan Bahasa telah dijelaskan bahwa penamaan tempat di ruang publik harus mencantumkan bahasa Indonesia.
Keberadaan bahasa Indonesia pun seharusnya mendapat dukungan dari bahasa daerah untuk memperkaya kosakata di dalam kamus. Namun, yang juga menjadi permasalahan adalah karena keberadaan bahasa daerah selain terus berkembang, sebagian lainnya mengalami kepunahan karena jumlah penutur yang semakin berkurang.

Berdasarkan data Badan Pengembangan dan Pembinaan Bahasa Kementerian Pendidikan dan Kebudayaan, pada tahun 2017, Indonesia memiliki 652 bahasa daerah. Jumlah tersebut seharusnya dapat memperkuat keberadaan bahasa nasional karena dalam ilmu bahasa, untuk memperkaya bahasa di dalam kamus, maka peran bahasa daerah sangat diperlukan.

Meskipun keberadaan bahasa Indonesia penting karena dalam Peraturan Pemerintah disebutkan salah satu fungsinya adalah untuk menjadikan bahasa Indonesia sebagai bahasa internasional, keberadaan bahasa inggris pun tetap penting salah satunya untuk menjaga komunikasi internasional dan untuk mengejar perkembangan baru, terutama penting bagi kaum muda (Kucukoglu, 2013). Selain itu, dengan menggunakan bahasa Inggris pun dapat menjadi peluang agar lebih banyak warga negara Indonesia yang memperkenalkan bahasa Indonesia kepada masyarakat internasional.

\section{Simpulan dan Saran}

Mengacu kepada situasi bahasa di tiga negara yang telah disebutkan sebelumnya, perencanaan bahasa Indonesia dapat mengacu pada negara Singapura, yng dengan beragam latar belakang bangsa tetapi dapat merencanakan bahasa dengan baik dengan menggunakan bahasa inggris dengan pengembangan/pencampuran berasal dari bahasa lokal (Singlish). Pun dengan melihat negara Aljazair, Indonesia seharusnya menyadari bahwa bahasa yang digunakan saat ini mengandung bahasa daerah dan juga merupakan warisan kolonial. Adapun berdasarkan situasi bahasa Spanyol, dalam melestarikan bahasa Indonesia, bahasa daerah pun perlu dipertahankan dengan cara penyebaran antargenerasi agar bahasa daerah tetap lestari dan dapat terus dimanfaatkan dalam pengembangan bahasa nasional.

\section{Referensi}

Aitsiselmi, F. (2006). Algeria: Language Situation. University of Bradford. Elsevier

Altinyelken, Hulya K., Sarah Moorcroft, \& Hilde van der Draai. (2014). The Dillemas and Complexities of Implementing Language-inEducation Policies: Perspectives From Urban and Rural Contexts in Uganda. International Journal of Educational Development, volume 36, 2014 
Azis, Yek Amin. Sejarah Kebijakan Bahasa di Indonesia dari Pra-Kemerdekaan sampai Sekarang dan Nilai-Nilai Pembelajarannya. Universitas Negeri Yogyakarta.

Kucukoglu, Bayram. (2013). The History of Foreign Language Policies in Turkey. Procedia Social and Behavior Sciences, volume 70, 2013.

Kurniawan, Khaerudin. (2017). Kebijakan Nasional Kebahasaan dan Pelindungan Bahasa Daerah. Jurnal Handayani, volume 7 issues 1, Juni 2017

Lim, L \& U. Ansaldo. (2006). Singapore: Language Situation. Universiteit van Amsterdam. Elsevier

Kemendikbud. (2018) Petunjuk Teknis Pengutamaan Penggunaan Bahasa Negara di Ruang Publik. Kemendikbud: Jakarta.

Republik Indonesia. (2014). Peraturan Pemerintah Nomor 57 Tahun 2014 tentang Pengembangan, Pembinaan, Dan Pelindungan Bahasa dan Sastra, Serta Peningkatan Fungsi Bahasa Indonesia. Lembar Negara Republik Indonesia Tahun 2014 Nomor 157. Sekretariat Negara. Jakarta.

Ridlo, Muhammad. (2018). Partisipasi Akademisi dalam Kebijakan Bahasa Indonesia. Seminar Internasional Riksa Bahasa 2018: Bandung

Sokolovska, Zorana. (2016). Imagining Europe's Linguistic Diversity in the Council of Europe's Parliamentary Assembly. Language \& Communication, 2016

Stewart, M. (2006). Spain: Language Situation. University of Strathclyde. Elsevier.

Sutama, Putu. (2018). Politik Bahasa, Regulasi, dan Eksistensi Bahasa Lokal. Universitas Udayana

Trudell, Barbara. (2009). Local-language Literacy and Sustainable Development in Africa. International Journal of Educational Development, volume 29, 2009 